\title{
Realidade e Ficção: Interfaces em Lima Barreto
}

\author{
Isabela da Hora Trindade ${ }^{1}$
}

RESUMO: Esse artigo visa a refletir acerca do fazer literário no que concernem aos quesitos biografia e ficção, tendo em vista a vida e a obra do escritor carioca Lima Barreto (1881-1922). Considerando a recorrente aproximação entre a trajetória do autor e os personagens por ele criados, buscaremos compreender as razões que o levaram a servir-se da experiência íntima como substância para nutrir sua obra.

ABSTRACT: The purpose of this article is to reflect on the literary making in what concern to the biography and fiction inquiries, having in view the life and the works of Brazilian writer Lima Barreto (1881-1922). Given on the recurrent approach between the trajectory of the author and the characters created by him, we will search to understand the reasons that led him to avail himself of his own anguishes, traumas and ideals as essence to feed his works.

PALAVRAS-CHAVE: Literatura Brasileira; Lima Barreto; Diário Íntimo.

KEYWORDS: Brazilian Literature; Lima Barreto; Diário Íntimo.

Empenhados em definir os elementos que constituem o estofo ficcional das obras literárias, muitos estudos têm se pautado na matéria social e histórica, ou seja, balizando-se em parâmetros circunstanciais, a fim de alcançar aquilo que estimulou a produção da obra. É certo que podemos reconhecer muito de realidade imbuída na trama da ficção, eis o porquê não raro nos deparamos com interpretações cujo norte sinaliza para determinantes contextuais - aspectos econômicos, políticos, culturais.

Apresentadas essas primeiras observações, cabe explicitar que as reflexões pontuais que ora serão expostas dizem respeito à tensão que envolve, no âmbito dos estudos literários, a fronteira entre realidade e imaginação,

1 Mestre, Área de Estudos Comparados de Literaturas de Língua Portuguesa, DLCV, FFLCH, USP. Título da dissertação: Páginas intimas: o diário extravagante de Lima Barreto. Contato: Isa_dahora@yahoo.com.br. 
articulando num sentido mais estrito biografia e ficção no tocante à trajetória do escritor carioca Lima Barreto (1881-1922).

A leitura atenta dos romances Recordações do escrivão Isaías Caminha, Triste fim de Policarpo Quaresma e Vida e morte de M. J. Gonzaga de Sá de autoria de Lima Barreto evidencia flagrantes semelhanças entre seus respectivos protagonistas e o autor. Entre as facetas representadas acompanhamos Isaías Caminha, personagem caracterizado como pobre e negro, que almejava ser reconhecido e, assim, redimir-se dos estigmas de origem social. Policarpo Quaresma, devotado obstinadamente à cultura brasileira, o que o leva ao exagero, por isso acaba internado no hospício. Gonzaga de Sá, funcionário público, detentor de considerável conhecimento acerca de diferentes assuntos, acaba marginalizado pela intelligentsia. Com efeito, o aspecto de autoconfissão que permeia as narrativas desse escritor carioca rendeu-lhe duras críticas à época em que viveu, conforme aponta o comentário do reputado crítico José Veríssimo (1857-1916) na ocasião da publicação de Recordações do escrivão Isaías Caminha:

O quadro saiu acanhado e defeituosamente
composto, e a representação sem serenidade,
pessoalíssima. Disto resultou graves máculas na
transposição - que é toda a grande arte e a dificuldade da
ficção do real para o fingido. E o seu livro tem
frequentemente mais ares de panfleto, e violento, do que
de romance, como a sua linguagem, ainda por isso, toma
o feitio daqueles jornalistas que com tão sincera e justa
paixão, mas com somenos arte, retrata e fustiga
(BARRETO, 2001, p. 30-31).

Não apenas Veríssimo, mas também outros críticos ao longo de diferentes décadas repetiram o mesmo julgamento negativo no que diz respeito à constante recorrência de fatos biográficos na obra de Lima Barreto: 
Lima Barreto é um autor vivo e penetrante, uma inteligência voltada com lucidez para o desmascaramento da sociedade e análise das próprias emoções, por meio de uma linguagem cheia de calor. Mas é um narrador menos bem realizado, sacudido entre altos e baixos, frequentemente incapaz de transformar o sentimento e a ideia em algo propriamente criativo. A análise dos escritos pessoais contribui para esclarecer isso, mostrando inclusive de que maneira o interesse dos seus romances pode estar em material às vezes pouco elaborado ficcionalmente, mas cabível enquanto testemunho, reflexão, impressão de cunho individual ou intuito social - como se o fato e a elaboração não fossem de todo distintos, para quem a literatura era uma espécie de paixão e dever; e até uma forma de existência pela qual sacrificou outras (HOUAISS e FIGUEIREDO, 1997, p.549$550)$.

Como é possível perceber, Candido destacou o caráter pessoal contido no fazer literário de Lima, capaz, segundo ele, de analisar as próprias emoções. Diante da validade de tais posturas, cremos ser instigante especular, a partir da perspectiva particular de Lima Barreto, as razões que o levaram a servir-se de sua experiência íntima como substância para nutrir sua obra. Essa é a principal questão que envolve o percurso desse estudo. Desse modo, cumpre-se aqui ressaltar que nossa intenção não se resume apenas em sublinhar uma vez mais essa relação estereotipada entre vida e obra, trata-se, sobretudo, de levantar hipóteses interpretativas mais amplas, no sentido de tentar compreender como os traços presentes nos escritos revelam as referências e intencionalidades de Lima Barreto num contexto mais abrangente, que se quer pessoal, racial e cultural de sua época.

Em face de nossa intenção, faz-se necessário descortinar o universo limabarretiano com o objetivo de entrevermos aquilo que ele desejava alcançar com seu métier, o que ele almejava imprimir em sua literatura e por que ele 
adotou tal postura. A fim de atingirmos nossos objetivos, lançaremos mão das reflexões confessionais anotadas nas páginas de seu Diário Íntimo, obra cuja forma já é capaz de assinalar aspectos válidos para esse estudo, conforme veremos adiante. A escolha do diário não é gratuita, uma vez que esse gênero permite um conhecimento íntimo do escritor na medida em que seu conteúdo revela segredos da consciência do autor, assim é possível resgatar características psicológicas daquele que se expõe nas páginas íntimas. Nesse sentido, pode ser tomado como documento não só psicológico, mas também sociológico, pois possibilita uma observação do universo que cerca o autor, ou seja, o leitor pode entrever um testemunho da época de escritura do diário. É “[n]o diário [que] o escritor faz-se ator, e expõe publicamente o reino do privado" (AGUIAR; MEIHY; VASCONCELOS, 1997, p. 165).

Um narrador em primeira pessoa que escreve sobre si e sobre fatos da realidade cotidiana mantendo certa periodicidade são características fundamentais na composição do diário. É importante destacar que o diário não se destina ao público, antes conserva caráter reservado. É o espaço onde o autor dirige-se a si próprio, colocando sua personalidade como o próprio objeto de seu olhar. Maciel (2002, p. 02) resume bem aquilo que vem a ser um diário: "[trata-se de] uma crônica cotidiana de uma experiência pessoal e quem o escreve (e se inscreve) interessa-se por anotar pequenas coisas do dia-a-dia ao lado das grandes dúvidas e indagações humanas". Adotando semelhante abordagem, Coutinho (2001, p. 593) o define como "gênero literário usado por escritores ou pessoas cultas para registrar pensamentos, acontecimentos de suas vidas ou de outrem, comentários sobre leituras feitas".

As anotações que compõem o Diário Íntimo de Lima Barreto estendem-se de 1900 a 1921. Haja vista tal número de anos, o leitor imaginará que essa obra é extremamente longa, dado se nesse intervalo de tempo Lima houvesse tomado nota diariamente. Contudo, logo que passamos a folheá-lo percebemos a falta de periodicidade das anotações. Essa irregularidade pode ser percebida pela ausência de notas ao longo dos anos 1901, 1902 e 1909, em nenhuma das edições 
foi verificado qualquer tipo de registro nesses anos ${ }^{2}$. Entretanto, observamos também que em nenhum dos anos constam anotações diárias; ao contrário, as notas são bem esparsas, o que quer dizer que há registros de alguns dias de determinados meses.

O ano de 1905 é o de registros mais abundantes. Somente no mês de janeiro verificamos vinte notas, além de outras não sequenciais ao longo dos meses de fevereiro, junho, julho e outubro. Outro traço relevante são as entradas das anotações que são assinaladas ora por dia e nome do mês, ora por somente dia ou por somente mês e há ainda entradas sem data.

Como podemos observar, a periodicidade da escritura de Lima configura-se bastante variável, fato que sinaliza para o tipo de vida levado pelo autor que teve uma existência conturbada, marcada especialmente pela doença do pai e pela falta de recursos financeiros da família ${ }^{3}$. Acreditamos ser possível atribuir aos diversos problemas pessoais do autor essa falta de regularidade das anotações. Vale ressaltar que Lima esteve internado no hospício por duas vezes por causa do alcoolismo - de agosto a outubro de 1914 e, posteriormente, de dezembro de 1919 a fevereiro do ano seguinte. É interessante destacar que ele percebe essa falta de sequência na escritura do diário, chegando a comentar:

Há mais de dez dias que não tomo notas. Nada de notável me há impressionado, de forma que me obrigue a registrar. Mesmo nos jornais nada tenho lido que me provoque assinalar, mas como entretanto eu queria ter um registro de pequenas, grandes, mínimas ideias, vou continuá-lo diariamente. ${ }^{4}$ (DI, p. 99 - 20 de fevereiro de 1905)

2 O Diário Íntimo possui três edições, a primeira data de 1953, editada pela editora Mérito S.A, a segunda é de 1956 e a terceira de 1961, ambas pela editora Brasiliense. Todas as edições foram organizadas por Francisco de Assis Barbosa.

3 Em 1902, João Henriques, pai de Lima Barreto, começou a padecer dos primeiros delírios. Em razão da doença do pai, Lima, por ser o filho mais velho, passa à chefia da casa o que o forçou a abandonar os estudos na Politécnica.

4 Todos os excertos citados do Diário Íntimo de Lima Barreto serão identificados pela sigla $D I$ e pertencem à segunda edição dessa obra. Incluiremos também a data referente ao excerto para situar melhor o leitor. 
Esse excerto demonstra que Lima atentava para esta característica do diário - a periodicidade, aspecto fundamental na confecção desse gênero que ele procurava respeitar. Lima expressa ainda que seu objetivo principal ao escrever o Diário era o de registrar suas ideias, razão pela qual escolhemos examinar esses escritos na intenção de encontrar pistas para compreender por que Lima construiu uma literatura tão ligada a sua experiência íntima. De fato, ao longo dessa obra, ele expõe suas reflexões mais particulares, seus desejos e anseios, os quais podem ser resumidos com palavras do próprio autor:

(...) que Deus me dê felicidade suficiente para pagar tudo que meu pai deve. E se eu isso fizer e se conseguir cercar-lhe o resto da vida da abundância que ele tem direito, eu só peço três coisas:

Um amor

Um belo livro

E uma viagem pela Europa e pela Ásia. (DI, p. 96 30 de janeiro de 1905)

Ultimo dia do mês em que, com certa regularidade, venho tomando notas diárias da minha vida, que a quero grande, nobre, plena de força e de elevação. (DI, p. 96 - 31 de janeiro de 1905)

Assim, ao lado de anotações relativas aos acontecimentos miúdos do cotidiano, ao comportamento de muitos de seus contemporâneos, às impressões de leituras, Lima demonstra seu sofrimento em virtude, sobretudo, de sua condição racial: "É triste não ser branco" (DI, p. 130 - 24 de janeiro de 1908), confessava ele nas páginas do Diário. Nesse sentido, são vários os desabafos lamentando a vida que levava, sentia-se essencialmente desajustado no seio familiar: 
Dolorosa vida a minha! Empreguei-me e há três meses que vou exercendo as minhas funções. A minha casa ainda é aquela dolorosa geena pra minh'alma. É um mosaico tétrico de dor e de tolice (DI, p. 41 - janeiro de 1904).

Esse sentimento lastimoso em relação à sua família perdura por toda a existência de Lima, cristalizando-se de maneira aterradora ao longo dos anos de escritura do Diário: "A minha vida de família tem sido uma atroz desgraça. Entre eu e ela há tanta dessemelhança, tanta cisão, que eu não sei como adaptar-me. Será o meu 'bovarismo'?” (DI, p. 91 - 26 de janeiro de 1905).

Diante de confissões tão consternadas é possível pensarmos que, no caso de Lima, escrever um diário seria um meio de exteriorizar suas angústias. Desse modo, a necessidade de desabafo estaria estreitamente ligada ao sentimento de que os fatos cotidianos eram difíceis de suportar, escrever seria antes de tudo uma forma de aliviar toda essa tensão que tanto lhe afligia. Contudo, somente o ato da escrita não lhe bastou - o álcool foi outro consolo encontrado para se alienar da realidade: "Vai me faltando a energia. Já não consigo ler um livro inteiro, já tenho náuseas de tudo, já escrevo com esforço. Só o álcool me dá prazer e me tenta ... Oh! Meu Deus ! Onde irei parar?" (DI, p. 136 - 16 de julho de 1908).

O deslocamento cultural sentido pelo autor, em razão da falta de consonância entre o espaço exterior onde vivia (o subúrbio) e sua condição de intelectual, pode ter sido o ponto de partida que o impulsionou a escrever um diário íntimo, segundo Coutinho (op. cit., p. 593) "forma de diário escrita secretamente". Como Lima não tinha com quem compartilhar seus desgostos, recorre às páginas de um diário para amenizar sua dor. A realidade é que ele tinha poucos amigos, como assinala Barbosa (2003, p. 156): “Poucas eram as casas que visitava - e assim mesmo nos tempos da primeira mocidade", entre os amigos destaca-se Noronha Santos, Otávio Carneiro e os irmãos Gomes Carneiros. 
Nessa obra encontramos uma tentativa de interlocução consigo, dito de outro modo, nesse movimento Lima narrador coloca-se como objeto e sujeito de seu olhar nos momentos de introspecção do indivíduo Lima Barreto: "[O diário] É, em primeiro lugar, uma espécie de desdobramento do seu autor, um ver-se em terceira pessoa, embora os diários sejam escritos em primeira" (AGUIAR; MEIHY; VASCONCELOS, op. cit. p. 165). Em uma das passagens do Diário observamos ainda o desejo velado de estabelecer certa interlocução com possíveis leitores dessa obra:

Se essas notas forem algum dia lidas, o que eu não espero, há de ser difícil explicar esse sentimento doloroso que eu tenho de minha casa, do desacordo profundo entre mim e ela; é de tal forma nuançoso a razão de ser disso, que para bem ser compreendido exigiria uma autobiografia, que nunca farei. Há cousas que sentidas em nós não podemos dizer. (...) Hoje, pois, como não houvesse assunto, resolvi fazer dessa nota uma página íntima, tanto mais íntima que é de mim para mim, do Afonso de vinte e três anos para o Afonso de trinta, de quarenta, de cinquenta anos. Guardando-as eu poderei fazer delas como pontos determinantes da trajetória da minha vida e do meu espírito, e outro não é o meu fito (DI, p. 77 - 3 de janeiro de 1905).

E completa, aconselhando aos leitores: "Aqui bem alto declaro que, se a morte me surpreender, não permitindo que as inutilize, peço a quem se servir delas que se sirva com o máximo cuidado e discrição, porque mesmo no túmulo eu poderia ter vergonha" (DI, p. 77 - 3 de janeiro de 1905). Aqui, é pertinente refletirmos sobre um aspecto apontado por Aguiar (op. cit., p. 166) referente aos escritores que se serviram desse gênero: "Escreve diário aquele que não sabe se ou como vai durar". Ora, sabemos que a vida de Lima não era 
nada tranquila, boêmio, atormentado pela falta de dinheiro, preocupado com a família, consumia-se pouco a pouco pela vida desregrada que levava.

O debruçar-se sobre as questões prementes contidas no Diário leva-nos a pensar na urgência de Lima em exteriorizar esse profundo desajustamento em razão da ambiguidade criada pelo seu status social enquanto mulato pobre e sua condição intelectual de homem de letras:

$\mathrm{Eu}$, entretanto, penso me ter salvo. Eu tenho muita simpatia pela gente pobre do Brasil, especialmente pelos de cor, mas não me é possível transformar essa simpatia literária, artística, por assim dizer em vida comum com eles, pelo menos com os que vivo, que, sem reconhecerem a minha superioridade, absolutamente não tem por mim nenhum respeito e nenhum amor que lhes fizesse obedecer cegamente (DI, p. 76 - 3 de janeiro de 1905).

Lima, letrado consoante aos padrões culturais europeus, mantém-se num espaço ambivalente - o da cultura letrada e o do subúrbio, como é possível observarmos no excerto supracitado. Contudo, sua condição racial sempre se colocou como fator mais significativo perante a sociedade, razão pela qual o autor nunca fora vinculado à elite de escritores brasileiros. Silva (2005) expõe claramente essa ambiguidade entre cor e classe ao focalizar as trajetórias de Lima Barreto e Cruz de Souza:

Cruz e Lima não eram indivíduos aculturados, ou seja, não saíram de uma cultura, com padrões definidos, para outra que apresentasse diferentes concepções de vida. Como brasileiros letrados da época, desenvolveram-se dentro dos adaptados padrões culturais europeus. Contudo, a pobreza e a situação racial do período em que viveram, submetendo-os a inúmeros constrangimentos e restrições, indicam que, por aquelas circunstâncias, estariam vinculados à cultura popular, pelo menos nos primeiros anos de vida, 
além de tê-las como referência pelos vínculos familiares. Contudo, o vetor de suas pretensões, muito cedo, foi o da cultura letrada. O desenvolvimento do exercício da escrita levou-os a dirigir suas atenções para as brechas da ideologia estética e seus pontos de desarticulação. Sabiam que as formas literárias tinham seus significados sociais, bem como que elas operavam no sentido de traduzir a conformação da hierarquia (Ibid., p. 188).

Acreditamos ser nesse sentido o lamento de Lima por não ser branco, pois ele sabia muito bem das benesses que poderia gozar caso não estivesse condenado ao estigma racial de sua cor. De fato, o Diário é pautado por esse sentimento de desacordo, assim como pelos anseios por reconhecimento intelectual, declarado fervorosamente pelo autor em entrevista concedida a revista Época em fins de fevereiro de 1916 em razão da publicação de Triste fim de Policarpo Quaresma:

Vim para a literatura com todo o desinteresse e com toda a coragem. O fim da minha vida é as letras. Eu não peço delas senão aquilo que elas me podem dar: glória! (...) Não quero ser deputado, não quero ser senador, não quero ser mais nada senão literato. Não peço às letras conquistas fáceis, não thes peço gloríolas, peço-lhes coisa sólida e duradoura. E posso falar de cadeira, porque, seu eu quisesse ter essas histórias, as teria de sobra. Eu abandonei tudo por elas; e a minha esperança é que elas me vão dar muita coisa. É o que me faz viver mergulhado nos meus desgostos, nas minhas mágoas, nos meus arrependimentos... ${ }^{5}$

Detecta-se aí uma tensão mantida, pois apesar das queixas em virtude das dificuldades encontradas dada sua condição racial, Lima mostra-se

5 O trecho citado dessa entrevista encontra-se na segunda edição do DI, p.183-184, em nota referente ao ano de 1916. 
absolutamente consciente de sua cor, ou seja, ele se aceita enquanto mulato, não deseja embranquecer para ser reconhecido. Nessa perspectiva, coloca-se na contramão do sistema social vigente, pois almeja a glória embora seja mulato. Ele, muito habilmente, compreendeu e sentiu o peso do passado de sua gente ${ }^{6}$ e, por conseguinte, das teorias raciais vindas da Europa que renegavam aos seus gozar plenamente da condição de cidadão mesmo num país de regime republicano. Nesse momento, um negro que ousasse aventurar-se como escritor, ofício reconhecidamente dos brancos, conforme assinala Silva (op. cit., p. 55), "será encarado como alguém investido de uma pressuposta inferioridade".

Talvez tenha sido esse enorme pesar diante dessas questões que tanto o inquietavam que o levou a buscar outras vias para abrandar seu sofrimento, visto assim parece-nos que o uso do espaço ficcional configurou-se essencial para Lima Barreto. Desse modo, as tortuosas tramas nas quais se viu enredado e nas quais também enredou seus personagens revela a urgência pela legitimação do $e u$, como bem destaca Hidalgo (2008):

\section{(...) fica difícil precisar o que veio antes: a} literatura como ferramenta para modificar o mundo imperfeito, como índice privilegiado da história social, ou o aproveitamento da escrita para a emergencial redenção de si e, por consequência, dos pobres, negros, marginais e loucos que socorreu... ao socorrer-se. Afinal, o eu era a origem, a causa principal desta literatura (Ibid., p. 228229).

A autora ressalta ainda que "Lima sobrecarregou a obra de um eu pleno de urgências, demasiado transparente para críticos ferrenhos" (Ibid., p. 229). A escrita, portanto, no diário ou na ficção ofereceu a Lima um espaço de atuação, permitindo-lhe extrapolar padrões intelectuais, sociais, literários; espaço cavado pela aporia desse eu marcado pelo excesso. Há, ainda, outro ponto a salientar:

${ }^{6}$ As avós de Lima, tanto materna (Geraldina Leocádia), quanto paterna (Carlota Maria dos Anjos) eram negras e ex-escravas. 
Lima, observador sagaz, logo percebeu no exercício literário a possibilidade de tudo dizer, expondo suas preocupações estéticas e pessoais, em alguma medida livre das mesuras sociais. Nesse cenário limabarretiano, a ficção funcionou como escape capaz de viabilizar outros desdobramentos para a literatura e, por conseguinte, para a sociedade brasileira, cujos olhares mantiveram-se voltados irrestritamente para o cenário europeu, sobretudo, ao longo das últimas décadas do século XIX e início do século seguinte. A respeito da postura distinta de Lima, Carvalho (1987) comenta:

O brilho republicano expressou-se em fórmulas europeias, especialmente parisienses. Mais que nunca, o mundo literário voltou-se para Paris, os poetas sonhavam viver em Paris e, sobretudo, morrer em Paris. Com poucas exceções, como o mulato Lima Barreto e o caboclo Euclides da Cunha, os literatos se dedicaram a produzir para o sorriso da elite carioca, com as antenas estéticas voltadas para a Europa (Ibid., p. 39).

Lima, por sua vez, volta-se para aquilo que nos é próprio, ou seja, para a realidade brasileira contemplando os elementos locais, dos quais se sobressaem as origens mestiças. Desse modo, recusa aquilo que é alheio à nossa identidade nacional essencialmente miscigenada, denunciando no espaço ficcional a europeização das consciências em solo auriverde.

Cumpre-se aqui ressaltar o esforço de Lima para construir uma literatura capaz de suscitar reflexões acerca das grandes indagações humanas, visto que concebia a Arte como fenômeno social. Vale acompanhar nas palavras do autor o significado que ele deseja imprimir à sua literatura:

Sendo assim, a importância da obra literária que se quer bela sem desprezar os atributos externos de perfeição de forma, de estilo, de correção gramatical, de ritmo vocabular, de jogo e equilíbrio das partes em vista de um fim, de obter unidade na 
variedade; uma tal importância, dizia eu, deve residir na exteriorização de um certo e determinado pensamento de interesse humano, que fale do problema angustioso de nosso destino em face do Infinito e do Mistério que nos cerca, e aluda às questões de nossa conduta na vida (BARRETO, 1956, p. 5859).

Desenha-se pela perspectiva particular desse eu combalido, para usar a expressão de Hidalgo, a urgência de transcender os estigmas por meio da Arte, um olhar que na presença da literatura nunca se arrefece, uma vez que o espaço da página branca representava para ele arena pública de combate. Daí decorre na vida-obra de Lima Barreto, a importância de se considerar sua biografia na análise de sua ficção, uma vez que esta fundamenta sua literatura. Desse modo, portanto, acreditamos estar diante de um autor cuja biografia seria irrelevante, se não fosse a sua obra ficcional norteada pelo ideal de que a literatura teria a faculdade de realizar "a comunhão dos homens de todas as raças e classes, fazendo que todos se compreendam, na infinita dor de serem homens, e se entendam sob o açoite da vida, para maior glória e perfeição da humanidade" (BARRETO, 2010, p. 58).

\section{Referências bibliográficas:}

AGUIAR, Flávio; MEIHY, José Carlos Sebe; VASCONCELOS, Sandra Guardini T. (orgs.). Gêneros de Fronteira: cruzamentos entre o histórico e o literário. São Paulo: Xamã, 1997.

BARRETO, Lima. Diário Íntimo. Rio de Janeiro: Editora Mérito S.A. São Paulo, 1953.

Diário Íntimo. São Paulo: Editora Brasiliense, 1956. Impressões de leitura. São Paulo: Editora Brasiliense, 1956. . Prosa Seleta. Rio de Janeiro: Editora Nova Aguilar, 2001. - Contos completos. Organização e introdução Lilia Moritz 
Schwarcz. São Paulo: Companhia das Letras, 2010.

BARBOSA, Francisco de Assis. A vida de Lima Barreto. Rio de Janeiro: José Olympio, 2003.

CANDIDO, Antonio. "Os olhos, a barca e o espelho". In: HOUAISS, Antonio e FIGUEIREDO, Carmen Lucia Negreiros de (coord.). Lima Barreto - Triste fim de Policarpo Quaresma (Edição crítica). Madri: Coleção Archivos/ Scipione Cultural, 1997.

CARVALHO, José Murilo de. Os bestializados. O Rio de Janeiro e a República que não foi. São Paulo: Companhia das Letras, 1987.

COUTINHO, Afranio e SOUSA, J. Galante de. Enciclopédia de Literatura Brasileira. São Paulo: Global Editora; Fundação Biblioteca Nacional, v. 1, 2001.

HIDALGO, Luciana. Literatura da urgência: Lima Barreto no domínio da loucura. São Paulo: Annablume, 2008.

MACIEL, Sheila Dias. Diários: escrita e leitura do mundo. Analecta, Mato Grosso do Sul, v. 3, n. 1, 2002. Disponível em: http://www.unicentro.br/editora/revistas/analecta/v3n1/artigo\%205\%20diar ios.pdf. Acesso em: 23 de junho de 2007.

SILVA, Luiz. A Consciência do Impacto nas Obras de Cruz e Souza e de Lima Barreto. Campinas, 2005. 232 f. Tese (Doutorado) - Instituto de Estudos da Linguagem, Universidade de Campinas. 